\title{
SAÚDE NÃO PRECISA SÓ DE DINHEIRO, MAS DE BOA GESTÃO
}

Coluna publicada em 22.10.2013: <http://www.conjur.com.br/2013-out-22/ contas-vista-saude-nao-dinheiro-boa-gestao $>$

Foi-se o tempo em que os médicos usavam termômetro, estetoscópio, medidor de pressão e, principalmente, conversa como seus únicos instrumentos de trabalho. A consulta e os exames eram um ato só. Diagnósticos se faziam a partir dos exames disponíveis: medição de temperatura, pressão e frequência cardíaca. O restante ficava por conta da experiência do clínico em sua conversa com o paciente. Bons tempos, alguns dirão, pois pelo menos tudo se resolvia mais rapidamente, sem necessidade de ir ao laboratório (eram poucos há duas décadas) para realização de dezenas de exames de nomes e siglas indecifráveis para os leigos. Incrível é constatar que, em não poucas vezes, faziam-se diagnósticos mais corretos e precisos do que atualmente. Mas isso é passado.

O fato é que a medicina se desenvolveu muito. Doenças que há duas ou três décadas eram fatais e incuráveis, como câncer e Aids, hoje não mais o são. É inegável a significativa melhoria na vida das pessoas trazida pelos avanços na área da saúde.

No entanto, esse progresso veio acompanhado de um significativo aumento nos custos e complexidade dos tratamentos, e o financiamento da saúde passou a ser um grave problema a ser enfrentado pelas pessoas e pelo Poder Público.

Deixando de lado os incontáveis litígios entre os particulares e os planos de saúde privados que abarrotam a Justiça brasileira, uma vez que o propósito desta coluna é tratar de Direito Financeiro, passemos para o financiamento do sistema público de saúde.

Nossa Constituição, que recentemente completou 25 anos, foi generosa com a saúde, dando-lhe atenção diferenciada. Em seus artigos $6^{\circ}$ e 196, reconhece a saúde 
como um direito social, direito de todos e dever do Estado, em perfeita consonância com os objetivos fundamentais da nossa República Federativa, enumerados no artigo $3^{\circ}$. Não seria exagero considerá-lo o mais importante direito assegurado pelo Estado brasileiro, e que exige atuação mais efetiva do Estado para torná-lo real, configurando um dos chamados "direitos fundamentais de segunda dimensão", conforme consagra a doutrina, e que, como tal, importa em custos. Que, nesse caso, como já se pode antever, não são pequenos. Médicos são profissionais de alta qualificação e, portanto, caros. Eles e os demais profissionais da área da saúde também são - ou deveriam ser - muito bem remunerados. No caso da saúde, os custos se agravam em muito diante das novas tecnologias, com aparelhos sofisticados e caros, o mesmo ocorrendo com os medicamentos necessários ao tratamento das doenças.

Garantir direito à saúde é, portanto, um ônus que pesa - e como - sobre os ombros do Estado brasileiro.

Ônus que nem todos os governos gostam de assumir. O maior exemplo é o que se pode observar nos Estados Unidos, que em 10 de outubro de 2013 viram paralisar a administração pública pela não aprovação de sua lei orçamentária pelo Parlamento, o que deixou o governo sem autorização para gastar dinheiro e, consequentemente, pagar as despesas imprescindíveis para o funcionamento do setor público. Motivo? Divergências com relação à implementação da legislação do chamado "Obamacare", que amplia a participação do setor público no sistema de saúde, facilitando o acesso e reduzindo os custos para a população, o que, consequentemente, aumenta as despesas do Estado americano. ${ }^{1}$

Sistematizado nos artigos 196 a 200 da Constituição, o sistema de saúde no Brasil prevê ampla atuação do Estado, que deve assegurar acesso universal e igualitário de toda a sociedade às políticas públicas voltadas à promoção, proteção e recuperação da saúde.

\footnotetext{
Aliás, para aproveitar a oportunidade, registro que, na coluna de 24 de setembro de 2013 , Planejamento municipal precisa ser levado a sério, chamei a atenção para o possível desinteresse da mídia para a importante data de 30 de setembro, quando seria - como efetivamente foi apresentada a proposta de plano plurianual de grande parte dos municípios do país, incluindo São Paulo, e dos projetos de lei orçamentária de Estados e municípios em todo o país. Infelizmente constato o acerto da previsão, pois, com raras exceções, o assunto foi tratado no noticiário. Mas há que se lamentar o fato de que, na mesma data, o Parlamento americano deliberou sobre a proposta orçamentária dos Estados Unidos e isso teve grande destaque no noticiário - e continua tendo até hoje, o que mostra estarmos dando mais importância e levando mais a sério o orçamento americano do que o nosso!
} 
Em um Estado federal como o Brasil, o financiamento público da saúde é especialmente complexo, dadas as peculiaridades do setor. Típica política pública exercida no âmbito do federalismo cooperativo que vigora em nosso país, é financiada e executada de forma conjunta por todos os entes da federação, o que, evidentemente, exige a participação, cooperação e coordenação entre eles, tanto na execução, quanto no financiamento.

Sendo os entes da federação dotados de autonomia, cujos governantes são eleitos democraticamente pela população, o que leva a um verdadeiro mosaico político, com prefeitos, governadores e presidente oriundos de partidos, ideologias e estilos diferentes, vê-se não ser fácil fazer com que todos atuem de forma coordenada e cooperativa em função de objetivos comuns.

O artigo 198 da Constituição dá as diretrizes gerais para o setor de saúde, cujas açôes e serviços públicos "integram uma rede regionalizada e hierarquizada e constituem um sistema único", regulamentado pelas Leis 8.080 e 8.142, de 1990, e pela Lei Complementar 141, de 2012, em que estão delineados as atribuições de cada ente federado e a forma de financiamento. ${ }^{2}$

A descentralização dos encargos em matéria de saúde é complexa e delicada, em face das especificidades do setor, uma vez que há múltiplos fatores a serem levados em consideração. Urgência, gravidade, complexidade, custo, demanda - há muitos itens a sopesar na delimitação de quem vai fazer o que e como. E imperfeições nessa alocação geram efeitos perversos para todos. Quantas vezes não se constata, na área da saúde, a ocorrência de fenômenos conhecidos dos estudiosos de federalismo fiscal como o free rider efect, ou "efeito carona", em que determinadas unidades da federação, especialmente os municípios, por fornecerem esse serviço público com competência e eficiência, atraem para si pacientes de outros municípios e acabam arcando com as despesas para o tratamento de um cidadão que não reside em seu território. Prefeitos que, em vez de se esforçarem para construir e manter postos de saúde e hospitais que prestem um serviço de boa qualidade, optam por comprar ambulâncias que levam os pacientes para serem atendidos em municípios vizinhos e, com isso, deixam de arcar com altas despesas, onerando outro ente da federação. Organizar todos esses fatores de modo a construir um

2 Vê-se ter o direito sanitário melhor sorte do que o direito financeiro, uma vez que, passados 25 anos da promulgação da Constituição, a legislação infraconstitucional regulamentando seus artigos está em vigor - ainda que tardiamente, pois a Lei Complementar 141 é bastante recente. Já o direito financeiro espera até hoje a lei complementar prevista no artigo $165, \$ 9^{\circ}$, essencial para a organização das leis orçamentárias, como já alertei em coluna anterior (Responsabilidade orçamentária precisa de melhorias, publicada em 12 de março de 2013). 
sistema eficiente e evitar externalidades de toda sorte é tarefa árdua, a exigir muito esforço, estudo e dedicação, que depende ainda de muita vontade política para ser implementado, tornando-o realidade.

Em matéria orçamentária, o Sistema Único de Saúde (SUS) é financiado com recursos "do orçamento da seguridade social, da União, dos Estados, do Distrito Federal e dos Municípios, além de outras fontes”, explicita o $\$ 1^{\circ}$ do artigo 198. Ou seja, por todos os entes da federação. Recursos estes cuja distribuição dá-se por um sofisticado mecanismo de financiamento, operacionalizado por meio do Fundo Nacional de Saúde e os fundos estaduais e municipais de saúde, compondo um sistema de transferências intergovernamentais fundo a fundo. Sem esquecer a intensa participação, com remuneração pelos cofres públicos, de entidades públicas, filantrópicas e organizações não governamentais.

A dificuldade em organizar as finanças na área da saúde tem sido ainda agravada pela forte interferência do Poder Judiciário, com decisões determinando o fornecimento de medicamentos e tratamentos caros, exigindo esforço redobrado dos gestores para realocar recursos orçamentários, alterando a programação financeira dos entes federados. A judicialização da saúde é tema de tal relevância e interesse que motivou a realização de audiência pública no Supremo Tribunal Federal em 2009 para debater o tema, que é por demais complexo para ser analisado nesta coluna, mas seguramente o farei oportunamente.

A saúde é priorizada em termos financeiros, contando com a garantia constitucional de aplicação mínima de recursos no setor por parte de todos os entes federados, na forma do artigo $198, \$ \$ 2^{\circ}$ e $3^{\circ}$ da Constituição e na Lei Complementar 141. Recentemente, a saúde foi contemplada com a destinação de parcela da arrecadação dos royalties de petróleo, na forma da Lei 12.858, de setembro de 2013, sem contar outras leis em vias de aprovação que dispõem no mesmo sentido, o que permite vislumbrar não ser por falta de recursos que nossa saúde anda mal.

Uma boa gestão desse complexo sistema de saúde pública é evidentemente fundamental, pois, como já tenho repetido exaustivamente em várias colunas, mais do que dinheiro, o setor público precisa é de uma administração mais eficiente, o que exige estudos, planejamento e medidas não só de curto, mas também e principalmente de médio e longo prazos.

Características que não parecem, à primeira vista, presentes no recente programa "Mais Médicos", implantado por medida provisória (MP 621/2013), com a "importação" de médicos realizada de forma ao que tudo indica apressada, deixando entrever que se trata de mais uma das tantas ações governamentais praticadas à revelia do sistema de planejamento governamental e voltadas a obter resultados 
imediatos de curto prazo, contrariando as boas técnicas e princípios da administração pública. ${ }^{3}$

Por que vai mal nosso sistema de saúde e qual o remédio para curá-lo são as grandes questôes que se colocam. Questões estas cujas respostas muito provavelmente não serão dadas pela medicina, mas sim pelo Direito Financeiro e pela Administração Pública.

3 Veja-se neste ponto a precisa e pertinente análise de Élida Pinto, Cláudia Pereira e Gabriel Léger: Importação de médicos tem contradiçôes constitucionais, publicada no site do Conjur em 6 de julho de 2013. 
